\title{
BARRIER FACTORS AFFECTING DEVELOPMENT OF INTELLIGENT TRANSPORT SYSTEM PROJECTS
}

\author{
Phong Thanh NGUYEN ${ }^{1,2^{*}}$, Thu Anh NGUYEN ${ }^{3,4}$, Thang Huynh Tat TRAN ${ }^{5}$ \\ ${ }^{1}$ Professional Knowledge \& Project Management Research Team (K2P), Ho Chi Minh City Open \\ University, Ho Chi Minh City, Vietnam, phong.nt@ou.edu.vn \\ ${ }^{2}$ Department of Project Management, Ho Chi Minh City Open University, Ho Chi Minh City, Vietnam, \\ phong.nt@ou.edu.vn \\ ${ }_{3}^{3}$ Building Information Modeling Lab, Ho Chi Minh University of Technology, Ho Chi Minh City, \\ Vietnam,nathu@hcmut.edu.vn \\ ${ }^{4}$ Vietnam National University Ho Chi Minh City, Linh Trung Ward, Thu Duc District, Ho Chi Minh \\ City, Vietnam, nathu@hcmut.edu.vn \\ ${ }^{5}$ Department of Construction Engineering and Management, Ho Chi Minh University of Technology, \\ Ho Chi Minh City, Vietnam, thtthang.sdh19@hcmut.edu.vn
}

\begin{abstract}
This paper identifies potential barrier factors affecting effectiveness and development (ED) of ITS projects as well as criteria for measuring ED of ITS projects in Ho Chi Minh City, Vietnam. The study discovers the barrier constructs, and analyzes data using the Partial Least Squares Structural Equation Modeling method (PLS-SEM). The results provides a general and comprehensive overview of the main issues of ITS, and identifies 28 barrier factors with five main constructs affecting ED of ITS projects, namely the lack of undivided attention from the government ( $A G)$, financial constraints for ITS $(F C)$, inadequate transport infrastructure (ITI), the over-development of urbanization (ODU), and the readiness and integration for ITS (RI). This paper fill the knowledge gap by discovering the causal relationships between barrier constructs and ED of ITS projects in Vietnam. Also it proposes several solutions for these issues, which are also a useful measurement tool for government agencies, planners, and traffic system designers to help them self-assess and make action plans now or in the near future.
\end{abstract}

Keywords: Barrier Factors, PLS-SEM, Intelligent Transport Systems (ITS), Smart City, Vietnam

Original scientific paper

Received: 27.11.2021

Accepted: date: 09.12.2021

Available online: 13.12 .2021

\section{Introduction}

In recent years, the changes in travelling methods in smart cities such as Intelligent Transport Systems (ITS), electric vehicles, and green mobility are positive signals for sustainable development in terms of environment and a national socio-economy Finck et al. (2020). In the concept of a smart city, Information Communication Technologies (ICTs) are the motivation to promote ITS applications (Alam et al., 2016). In addition, the remarkable development of ICTs has contributed to the management of urban issues related to people, energy, buildings, and technical infrastructure. Without crucial policies and significant advances in technology, few 
possibilities remain to separate transport growth from an increase in fume emissions as $95 \%$ of transport energy comes from fossil fuels (Metz et al., 2007). The rapid urbanization process creates numerous problems from solving traffic congestion to managing national roads (Karim \& Fouad, 2018b; Lin et al., 2017). According to the United Nations, $68 \%$ of the global population will be urban dwellers by 2050, which eventually means a depletion of resources, creating burdens on existing infrastructure. In that context, many researchers such as as Alam et al. (2016); John et al. (2019); Sampson (2019) claimed that ITS is an essential part of forming a typical "smart" city. Therefore, this study aims to discover the impact of barrier factors on Intelligent Transport Systems (ITS) projects in Vietnam resulting in a branch database to develop the standards of a smart city (SC).

\section{Literature review}

The concept of ITS was originally proposed by researchers in the US in the 20th century (Alam et al., 2016). ITS consists of a set of technologies and applications aimed at improving safety and mobility in traffic; as well as increasing labor productivity and reducing the negative impacts of traffic. Regarding Intelligent Transport Systems, since the end of the 20th century, governments from developed countries have been aware that ITS is a product of a contemporary society which maximizes operating efficiency of the transport system, ensures traffic safety, and improves social efficiency. With the application of high technology, ITS makes a huge contribution toward creating a sustainable transportation system characterized as safe, smooth, and environmentally protective. After 27 years of ITS World Congress establishment and development, the Congress offered excellent ideas for the benefit of the community in Hamburg in October 2021. Furthermore, new concepts such as Automated \& Connected Driving, Mobility on Demand, Mobility as a Service, Goods Journey from ports to customers, Intelligent Infrastructure, New Services from new technologies, and Solutions for Cities and Citizens were born and applied experimentally in countries with sufficient financial capacity (Foster, 2021). All topics in the ITS Congress are in accordance with the ISO/TC 204 standard, "ITS is designed to rapidly improve road traffic safety, transport efficiency and comfort, and to significantly contribute to energy and environmental conservation through traffic flow facilitation, such as elimination of traffic jams, by using communication technologies to link between people, infrastructure, and vehicles."

ITS integration into a smart city will be efficient only when it can achieve the purpose according to the ISO 37122:2019 standard, "smart city that increases the pace at which it provides social, economic, and environmental sustainability outcomes and responds to challenges such as climate change, rapid population growth, and political and economic instability by fundamentally improving how it engages society, applies collaborative leadership methods, works across disciplines and city systems, and uses data information and modern technologies to deliver better services and quality of life to those in the city (residents, businesses, visitors), now and for the foreseeable future, without unfair disadvantage of others or degradation of the natural environment." In the context of smart systems, compatibility and synchronization between interconnected systems in traffic is essential for ITS integration into a smart city, a combination of six smart aspects including governance, citizenship, transportation infrastructure, environment, quality of life, and economy. Initial definitions of a "smart city" can be developed from the definition of a "wired city" which focuses only on urban spatial networks. With regard to "intelligent cities," the previous concepts evolved by considering the level of literacy of the digital city including population, institutional arrangements, and infrastructure. It is also embedded as systems are enhanced, stimulating all levels of a system's 
inputs including human and social capitals, with ICT infrastructure to produce a better quality of life as well as more sustainable economic development. As a high-tech industry, ITS is often regarded as expensive, or even exorbitant, ITS implementation should proceed in several phases. Therefore, the governing bodies are expected to have a long-term vision to ensure the smooth combination of all stages, where the later stages exploit the matter and support the previous ones. It is mandatory for every ITS system to acquire high compatibility since ITS involves a combination of modern techniques targeted at providing optimized and comprehensive urban mobility, and offers safety, comfort, and convenience for both traffic participants and people living in smart cities.

Many researchers believe that a national ITS master plan must integrate domestic and international reference architecture, and a combination of an analysis of barrier factors and success, so that ITS can progress rapidly (Booysen et al., 2013; El.Husseiny et al., 2017; Karim \& Fouad, 2018b). In anticipation of the remarkable development of ITS, planners built a sociotechnical road map to integrate the policies, technical infrastructures, and accompanied services (Tuominen \& Ahlqvist, 2009). The analysis of the relationship between ITS and the development of society has posed challenges in designing traffic policy for smart cities (Dapice et al., 2010; Finck et al., 2020; Sun, 2011). Along with the cooperation for mutual development, the transport system will be increasingly expanded for private parties, which is considered as a move representing the mass profits from ITS investment (Antoniou et al., 2012). Effective policies implementation depends on ICT which offers, to a great extent, the potential of road safety improvement. The primary tools used in ITS are GPS and VANET, with the aim of offering solutions to reduce traffic problems, including traffic congestion and accidents, as it aims to solve the aforementioned problems by improving vehicle mobility, making cities smarter and safer (Khekare \& Sakhare, 2013; Khorasani et al., 2013). In recent years, the emergence of electric and hybrid vehicles has led to the increase in new services; therefore, sensors and embedded systems have gradually become popular due to the high accuracy in traffic accident warning, and energy regulation of fossil fuel vehicles (B, AJ, \& N, 2017; Qin \& Zhang, 2011). On the other hand, it remains a concern that too much concentration on describing spatial data, and exploring the types of data and information used in urban planning and management, does not emphasize the human factor. To guarantee the long-term profitability of ITS projects, both socio-economic efficiency and the benefits that ITS brings to the people should be taken into consideration. The proposed solutions are not really effective and unlikely to handle the actual collected data sources; furthermore, traffic congestion still occurs and tends to get worse in big cities. The results of this study clearly explain the growing interest among policymakers, experts, and researchers in exploring the potential of ITS.

\section{Research Method}

\subsection{Data Collection}

The barrier identification to effectiveness and development (ED) of ITS projects applied the systematic literature review approach suggested by Kitchenham, 2004, according to the following steps. Initially, academic databases are collected in paper and e-book formats including journal articles, conference papers, science magazines, and reports which come from ASCE, Springer, IEEE, Elsevier... and other experts' opinions in Vietnam. Keywords for the search include: "intelligent transportation systems," "smart cities and intelligent transportation systems," "urban planning," "green mobility," "smart mobility," "the technical infrastructure," "barrier factors," "success factors," "IoT," "ICT," "wireless network," "rating index smart city," 
"smart/ sustainable city policies," and "project risk." After searching for terms according to titles, abstracts, and keywords of articles, 105 related articles were selected. Second, the shortlist for the most appropriate articles depends on six criteria: (1) articles must be in English; (2) published from 2009 to 2020; (3) relevant to developing and developed countries; (4) be road, tunnel, subway, and elevated road types; (5) reflect the availability of data calculation from data collection; (6) include Meniscus duplicate both the content and implementation method. As a result, 20 articles were retained to further analyze the factors affecting the effectiveness and development of ITS. Third, the authors consulted experts in traffic projects in general and in civil construction in particular in Vietnam. The results obtained from five main groups from 28 factors were divided in order by importance levels from the most to the least important with the agreement of 10 experts consulted, that are concerned with the difficulties that countries around the world face when ITS development, application, and implementation come into practice. Finally, the table below summarizes the barriers to the development of an ITS project.

Table 1. List of potential factors affecting the effectiveness \& development of ITS projects

\begin{tabular}{|c|c|c|}
\hline Code & Factor & References $\left(^{*}\right)$ \\
\hline \multicolumn{3}{|c|}{ Potential factors affecting ITS } \\
\hline AG & \multicolumn{2}{|c|}{ The lack of undivided attention from the government } \\
\hline AG_F1 & $\begin{array}{l}\text { The unclear legal structure and institutions of } \\
\text { country. }\end{array}$ & [6], [17], [20], [21] \\
\hline AG_F2 & Keeping the inherent bureaucracy. & {$[4],[13],[16],[21]$} \\
\hline AG_F3 & $\begin{array}{l}\text { Limited capacity and conservative attitude of } \\
\text { authorities at all levels. }\end{array}$ & [4], [13], [16], [8], [21] \\
\hline AG_F4 & The active participation of agencies is lacking. & {$[4],[13],[16],[17],[18],[21]$} \\
\hline AG_F5 & $\begin{array}{l}\text { Abuse of authority for personal benefit and } \\
\text { corruption. }\end{array}$ & [4], [13], [16], [17] \\
\hline AG_F6 & $\begin{array}{l}\text { Policies related to sustainability for roads are not } \\
\text { really effective since they prioritize economic } \\
\text { development. }\end{array}$ & {$[1],[18],[20],[8],[21]$} \\
\hline AG_F7 & $\begin{array}{l}\text { Policies with cross-sectoral consistency at } \\
\text { government levels are lacking. }\end{array}$ & [4], [13], [16], [21] \\
\hline AG_F8 & $\begin{array}{l}\text { Budget allocation for the development of a smart } \\
\text { transport infrastructure project is not reasonable. }\end{array}$ & $\begin{array}{l}{[4],[13],[16],[20],[8],[11],} \\
{[21]}\end{array}$ \\
\hline AG_F9 & $\begin{array}{l}\text { Difficulty in communicating between involved } \\
\text { stakeholders and technology. }\end{array}$ & $\begin{array}{l}\text { [6], [10], [13], [18], [20], [8], } \\
{[11]}\end{array}$ \\
\hline FC & \multicolumn{2}{|c|}{ Financial constraints for ITS } \\
\hline FC_F10 & Limited demand for automation. & [1], [4], [13], [16], [17], [21] \\
\hline FC_F11 & $\begin{array}{l}\text { Enormous expenditure for ITS implementation/ } \\
\text { application. }\end{array}$ & [2], [3], [6], [13], [11], [21] \\
\hline FC_F12 & $\begin{array}{l}\text { Disruption during the implementation of the ITS } \\
\text { project. }\end{array}$ & [5], [13], [10], [21] \\
\hline FC_F13 & $\begin{array}{l}\text { Resources insufficiency for the maintenance and } \\
\text { operation process. }\end{array}$ & [2], [6], [13], [8], [21] \\
\hline ITI & \multicolumn{2}{|c|}{ Inadequate/ incomplete transport infrastructure } \\
\hline ITI_F14 & Undeveloped infrastructure systems. & $\begin{array}{l}{[2],[3],[4],[5],[6],[7],[15],} \\
{[18],[14],[19],[21]}\end{array}$ \\
\hline ITI_F15 & Challenges in community space rearrangement. & $\begin{array}{l}\text { [2], [4], [5], [6], [7], [15], [18], } \\
{[11],[12]}\end{array}$ \\
\hline ITI_F16 & End users do not want to change. & [6], [9], [20] \\
\hline
\end{tabular}




\begin{tabular}{|c|c|c|}
\hline ITI_F17 & $\begin{array}{l}\text { People awareness of a clear explanation about ITS } \\
\text { benefits. }\end{array}$ & [6], [9], [20], [8], [19] \\
\hline ITI_F18 & The "slum" and "super slum" in the inner city. & $\begin{array}{l}{[2],[4],[5],[6],[7],[9],[15],} \\
{[21]}\end{array}$ \\
\hline ODU & \multicolumn{2}{|c|}{ The over-development of urbanization } \\
\hline ODU_F19 & Urban boom and growth. & $\begin{array}{l}{[1],[2],[5],[13],[12],[19],} \\
{[21]}\end{array}$ \\
\hline ODU_F20 & ITS adaptation to urban growth. & {$[3],[5],[10],[13],[12],[21]$} \\
\hline ODU_F21 & The need for new transport infrastructure. & $\begin{array}{l}\text { [4], [5], [6], [7], [9], [15], [20], } \\
\text { [12] }\end{array}$ \\
\hline ODU_F22 & $\begin{array}{l}\text { The current policies for the transport system are } \\
\text { incapable of catching up with technological } \\
\text { changes. }\end{array}$ & [1], [17], [18], [20], [8], [21] \\
\hline RI & \multicolumn{2}{|c|}{ The readiness and integration for ITS } \\
\hline RI_F23 & $\begin{array}{l}\text { Differences in ITS translations (understandings) } \\
\text { from involved stakeholders. }\end{array}$ & {$[5],[10],[13],[18],[19]$} \\
\hline RI_F24 & $\begin{array}{l}\text { Simultaneous application of old and new } \\
\text { methods. }\end{array}$ & $\begin{array}{l}{[1],[5],[10],[13],[20],[8],} \\
{[19]}\end{array}$ \\
\hline RI_F25 & Skepticism of new technologies. & {$[6],[9],[20]$} \\
\hline RI_F26 & Poor ITS customization. & {$[5],[10],[13],[21]$} \\
\hline RI_F27 & $\begin{array}{l}\text { Information insufficiency in existing/ current and } \\
\text { new ITS application. }\end{array}$ & {$[3],[5],[10],[13],[18],[21]$} \\
\hline RI_F28 & Limitation in insurance scope. & {$[5],[10],[13],[21]$} \\
\hline ED & \multicolumn{2}{|c|}{ Factors affecting effectiveness \& development of ITS } \\
\hline
\end{tabular}

A general ineffective strategy due to the lack of integration of domestic as well as international reference architectures and factors contributing to

ED1 its success: A national ITS general plan should cover continuous implementation from the first [1], [4], [6], [13], [16], [17], [18], [20], [11], [21] phase of ITS to the planning of new technologies and services.

Insufficiency of a clear description of the benefits that ITS brings from policymakers: Preventing ITS to bring economic benefits, put positive effects on

ED2 people's spiritual life through optimization of existing infrastructure and transportation system, and cause wastes of intangible costs such as traffic [2], [3], [4], [5], [9], [10], [13], [15], [16], [17], [18], [20], [8], [11], [21] accidents, congestion, environmental pollution. Delay in the development of a national ITS data center: Prolonged implementation of methods and ED3 tools for collecting traffic data is due to the fact that existing infrastructure does not catch up with [1], [2], [4], [7], [9], [13], [16], [17], [8], [11], [19], [21] the technology.

The efficiency of ITS projects implementation decreased since investors reduced expectations on

ED4 ITS investments: It takes many years for the application of technology from concept to practice. During that period, it is required to improve [17], [18], [20], [11], [14], [21] technology in order to increase productivity and 


\begin{tabular}{|c|c|c|}
\hline & reduce costs. & \\
\hline ED5 & Tension between involved parties. & $\begin{array}{l}{[1],[4],[6],[10],[13],[16],} \\
{[17],[18],[20],[11],[21]}\end{array}$ \\
\hline ED6 & $\begin{array}{l}\text { Challenge in coping with old and degraded } \\
\text { infrastructure. }\end{array}$ & $\begin{array}{l}{[1],[2],[3],[4],[5],[6],[7],} \\
{[9],[15],[18],[20],[8],[12],} \\
{[14],[19],[21]}\end{array}$ \\
\hline
\end{tabular}

\section{References $\left(^{*}\right)$}

[1]: (Tuominen \& Ahlqvist, 2009); [2]: (Hsu et al., 2010); [3]: (Sun, 2011); [4]: (Hidalgo \& Huizenga, 2012); [5]: (Sen \& Raman, 2012); [6]: (Booysen et al., 2013); [7]: (Far et al., 2013); [8]: (Grant-Muller \& Usher, 2013); [9]: (Dubow, 2014); [10]: (Dassani et al., 2015); [11]: (Mangiaracina et al., 2016); [12]: (Roselló et al., 2016); [13]: (El.Husseiny et al., 2017); [14]: (Lin et al., 2017); [15]: (Karim \& Fouad, 2018a); [16]: (Karim \& Fouad, 2018b); [17]: (Schlingensiepen et al., 2018); [18]: (Mathew, 2019); [19]: (John et al., 2019); [20]: (Finck et al., 2020); [21]: Expert opinions.

\subsection{Conceptual Method}

Structural equation modeling (SEM) is a multivariate analysis technique used to analyze structural relationships (Hair et al., 2017). The PLS-SEM method is a second-generation technique which was developed to analyze multidimensional relationships between multiple variables in a model, especially in the social sciences (Rigdon, 2012). In addition, the PLS-SEM method is also applied in construction management (Zeng et al., 2021). Path models are graphs that visually display the relationships of hypotheses and constructs, including a measurement model and a structural model (Latan \& Noonan, 2017). Path model identification depends on the effectiveness and development (ED) of ITS projects towards effects causing a lack of undivided attention from the government (AG), financial constraints for ITS (FC), inadequate/incomplete transport infrastructure (ITI), the over-development of urbanization (ODU), and the readiness and integration for ITS (RI) which are detailed in Table 1.

The PLS path model was established, and estimation was executed using the SmartPLS 3 software. The path model identifies exogenous latent variables (AG, FC, ITI, ODU, RI), endogenous latent variable (ED), and indicators (F1 - F28/ ED1 - ED6), and is illustrated in Figure 1. This study hypothesized the following five relationships for the structural model:

Hypothesis 1 (H1) The lack of undivided attention from the government (AG) has a direct influence on effectiveness and development (ED);

Hypothesis 2 (H2) Financial constraints for ITS (FC) have a direct influence on effectiveness and development (ED);

Hypothesis 3 (H3) Inadequate/incomplete transport infrastructure (ITI) has a direct influence on effectiveness and development (ED);

Hypothesis 4 (H4) The over-development of urbanization (ODU) has a direct influence on effectiveness and development (ED)

Hypothesis 5 (H5) the readiness for and integration of ITS (RI) has a direct influence on effectiveness and development (ED). 


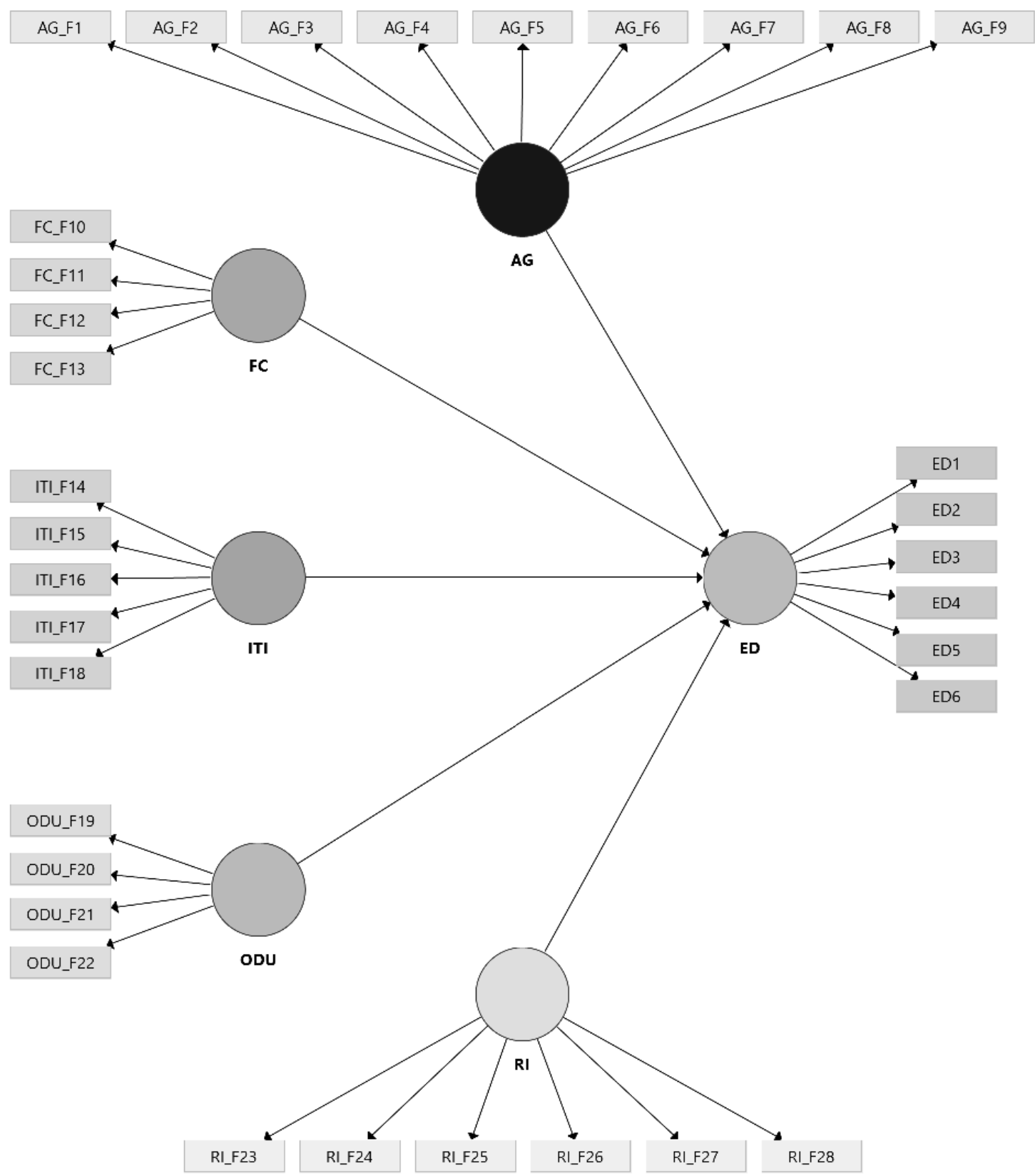

Figure 1. Conceptual model

\subsection{Questionnaire Design and Sampling}

The questionnaire-based survey was conducted to collect primary data from experts in ITS projects, including state officials and employees, engineers and architects related to construction in Project Management Consulting and Design, and experienced individuals or professionals. In the first step, barriers affecting ITS effectiveness and development are clearly explained, which are presented in Section 3.1. The questionnaire was devised from the perception of a construction expert in traffic projects in general and in civil construction in particular in Vietnam. The first section of the questionnaire consists of general information such as the participant's major, working experience, type of organization, and working position. The second section of the questionnaire includes core questions presented in Table 1, using a Likert 
scale (from totally disagree to totally agree, equivalent to 1 to 5 , respectively) to assess the influence of potential factors affecting ITS and its effectiveness and development.

Sampling technique used for this questionnaire is classified into two types. Non-probability sampling $(30 \%)$ is randomly applied for construction practitioners while probability sampling $(70 \%)$ is given to experts from whom primary data was collected. The samples were gathered from online sources and email. After two months, 205 responses were acquired, and finally, 150 valid responses were kept, representing a response rate of more than $73 \%(150 / 205)$. The sample size was applied by the method of 10 times the largest number of structural paths directed; therefore, five hypotheses in a structural model in this research required a minimum sample size of 50, and the result is considered as input for final analysis. According to the demographic information of respondents presented in Table 2, among 150 valid responses, there were 54 respondents having three to five years of experience (36\%), 36 respondents having six to 10 years of experience (24\%), and 18 respondents having more than 10 years of experience $(12 \%)$, and others. The results revealed that most of the respondents were experienced in the construction field and were deliberate in answering the questions, so the results can be considered as objective and reliable.

Table 2. The demographic information of respondents

\begin{tabular}{|c|c|c|c|}
\hline Characteristic & Frequency & Percentage & Cumulative Percentage \\
\hline \multicolumn{4}{|l|}{ Major } \\
\hline 1. Project Management & 37 & 24.67 & 24.67 \\
\hline $\begin{array}{l}\text { 2. Civil and Industrial } \\
\text { Construction }\end{array}$ & 6 & 4.00 & 28.67 \\
\hline 3. Transport Construction & 60 & 40.00 & 68.67 \\
\hline 4. Architecture & 30 & 20.00 & 88.67 \\
\hline 5. Regional and Urban Planning & 16 & 10.67 & 99.33 \\
\hline 6. Maritime Construction & 1 & 0.67 & 100.00 \\
\hline \multicolumn{4}{|l|}{ Working experience (years) } \\
\hline 1. Less than 3 years & 42 & 28.00 & 28.00 \\
\hline 2. From 03 to 05 years & 54 & 36.00 & 64.00 \\
\hline 3. From 06 to 10 years & 36 & 24.00 & 88.00 \\
\hline 4. More than 10 years & 18 & 12.00 & 100.00 \\
\hline \multicolumn{4}{|l|}{ Type of organization } \\
\hline $\begin{array}{l}\text { 1. State management agencies in } \\
\text { charge of specialized fields }\end{array}$ & 15 & 10.00 & 10.00 \\
\hline $\begin{array}{l}\text { 2. Investor / member of project } \\
\text { management board }\end{array}$ & 32 & 21.33 & 31.33 \\
\hline 3. Design consultant/ supervisor & 51 & 34.00 & 65.33 \\
\hline 4. Construction contractor & 42 & 28.00 & 93.33 \\
\hline 5. University/ College & 10 & 6.67 & 100.00 \\
\hline \multicolumn{4}{|l|}{ Working position } \\
\hline 1. Staff & 111 & 74.00 & 74.00 \\
\hline $\begin{array}{l}\text { 2. Head/Deputy Head of } \\
\text { Technical Department }\end{array}$ & 21 & 14.00 & 88.00 \\
\hline 3. Project Director or Site Manager & 6 & 4.00 & 92.00 \\
\hline $\begin{array}{l}\text { 4. Board of Directors of the } \\
\text { company }\end{array}$ & 3 & 2.00 & 94.00 \\
\hline 5. A university/ college lecturer & 9 & 6.00 & 100.00 \\
\hline
\end{tabular}




\section{Data Analysis}

Assessment of the outer measurement model and inner structural model is mandatory in estimating structural equation models when applying PLS-SEM (Henseler et al., 2009). In this study, SmartPLS software is utilized in analysis and assessment.

\subsection{Outer measurement model}

The process of assessment of outer measurement is conducted in three steps.

Step 1: Convergent validity

The initial step to eliminate indicators is convergent validity identification, a measurement tool which correlates positively with other measures of the same construct ( Hair et al., 2017). If outer loadings on the construct are high, it means that associated indicators measure the same construct which is considered as indicator reliability. According to recommendations by Hair et al. (2017), when the value of outer loading is higher than or equal to 0.70 , the indicator is accepted; otherwise, if the value is between 0.40 and 0.70 , indicators should be considered to be eliminated, and PLS-SEM needs re-analyzing. In this study, to guarantee the reliability of the model, outer loading with the value below 0.70 were eliminated. Along with the outer loading examination, the average variance extracted (AVE) must also be taken into consideration. Hair et al., (2009) suggested a "rule of thumb" in order to create an AVE rating threshold. When the value of AVE is higher than or equal to 0.50, the variation of each indicator is explained above $50 \%$ by the construct, where the model can reach accuracy in convergence.

Table 3. The value of cross loadings

\begin{tabular}{ccccccc}
\hline Code & AG & ED & FC & ITI & ODU & RI \\
\hline AG_F1 & $\mathbf{0 . 7 3 8}$ & 0.365 & 0.141 & 0.138 & 0.124 & 0.135 \\
\hline AG_F2 & $\mathbf{0 . 7 3 2}$ & 0.441 & 0.286 & 0.223 & 0.136 & 0.242 \\
\hline AG_F3 & $\mathbf{0 . 7 5 1}$ & 0.395 & 0.217 & 0.213 & 0.191 & 0.192 \\
\hline AG_F4 & $\mathbf{0 . 7 4 5}$ & 0.406 & 0.256 & 0.207 & 0.236 & 0.139 \\
\hline AG_F5 & $\mathbf{0 . 7 8 3}$ & 0.433 & 0.212 & 0.262 & 0.204 & 0.275 \\
\hline AG_F6 & $\mathbf{0 . 7 4 3}$ & 0.508 & 0.300 & 0.262 & 0.211 & 0.117 \\
\hline AG_F7 & $\mathbf{0 . 8 6 9}$ & 0.494 & 0.302 & 0.261 & 0.203 & 0.222 \\
\hline AG_F8 & $\mathbf{0 . 7 6 5}$ & 0.409 & 0.157 & 0.150 & 0.155 & 0.192 \\
\hline ED1 & 0.508 & $\mathbf{0 . 8 1 5}$ & 0.623 & 0.542 & 0.327 & 0.264 \\
\hline ED2 & 0.482 & $\mathbf{0 . 7 9 8}$ & 0.507 & 0.507 & 0.335 & 0.290 \\
\hline ED3 & 0.387 & $\mathbf{0 . 7 8 4}$ & 0.497 & 0.501 & 0.283 & 0.269 \\
\hline ED4 & 0.469 & $\mathbf{0 . 8 0 1}$ & 0.482 & 0.558 & 0.321 & 0.189 \\
\hline ED5 & 0.414 & $\mathbf{0 . 7 2 3}$ & 0.395 & 0.297 & 0.339 & 0.279 \\
\hline ED6 & 0.389 & $\mathbf{0 . 7 7 2}$ & 0.500 & 0.451 & 0.244 & 0.165 \\
\hline FC_F10 & 0.287 & 0.543 & $\mathbf{0 . 8 0 9}$ & 0.327 & 0.115 & 0.072 \\
\hline FC_F11 & 0.300 & 0.559 & $\mathbf{0 . 8 5 8}$ & 0.402 & 0.103 & 0.029 \\
\hline FC_F12 & 0.261 & 0.538 & $\mathbf{0 . 8 7 2}$ & 0.405 & 0.106 & 0.101 \\
\hline FC_F13 & 0.207 & 0.550 & $\mathbf{0 . 8 5 2}$ & 0.381 & 0.081 & 0.061 \\
\hline ITI_F14 & 0.208 & 0.532 & 0.412 & $\mathbf{0 . 8 3 8}$ & 0.161 & -0.038 \\
\hline ITI_F15 & 0.265 & 0.475 & 0.391 & $\mathbf{0 . 7 5 1}$ & 0.307 & 0.123 \\
\hline ITI_F16 & 0.215 & 0.542 & 0.398 & $\mathbf{0 . 8 6 1}$ & 0.272 & 0.105 \\
\hline ITI_F17 & 0.179 & 0.482 & 0.323 & $\mathbf{0 . 8 3 8}$ & 0.138 & 0.045 \\
\hline ITI_F18 & 0.299 & 0.481 & 0.294 & $\mathbf{0 . 7 8 9}$ & 0.167 & 0.078 \\
\hline & & & & & &
\end{tabular}




\begin{tabular}{ccccccc}
\hline ODU_F19 & 0.175 & 0.305 & 0.054 & 0.226 & $\mathbf{0 . 7 7 2}$ & 0.258 \\
\hline ODU_F20 & 0.143 & 0.296 & 0.123 & 0.175 & $\mathbf{0 . 8 3 3}$ & 0.269 \\
\hline ODU_F21 & 0.292 & 0.354 & 0.096 & 0.183 & $\mathbf{0 . 8 3 1}$ & 0.275 \\
\hline ODU_F22 & 0.178 & 0.351 & 0.125 & 0.267 & $\mathbf{0 . 8 9 6}$ & 0.239 \\
\hline RI_F23 & 0.245 & 0.266 & 0.041 & 0.107 & 0.256 & $\mathbf{0 . 8 3 0}$ \\
\hline RI_F24 & 0.185 & 0.184 & -0.009 & 0.014 & 0.252 & $\mathbf{0 . 8 2 9}$ \\
\hline RI_F25 & 0.190 & 0.282 & 0.101 & 0.093 & 0.271 & $\mathbf{0 . 8 5 2}$ \\
\hline RI_F26 & 0.165 & 0.242 & 0.051 & 0.026 & 0.266 & $\mathbf{0 . 8 5 3}$ \\
\hline RI_F27 & 0.237 & 0.295 & 0.108 & 0.056 & 0.256 & $\mathbf{0 . 8 2 5}$ \\
\hline
\end{tabular}

Note: The value in bold is outer loadings $>0.70$

Based on the above conditions, table 3 is the analysis result after omitting the AG_F9 and RI_F28 indicators because the outer loading is less than 0.70. At step 1 of the analysis of the outer measurement model, the path model is re-conceptualized with 26 indicators for five exogenous latent variables (AG, FC, ITI, ODU, RI) and six indicators for a endogenous latent variables (ED). The model in Figure 2 will be used for analysis for the next steps. Table 6 reveals that the AVE value of each construct is between 0.588 and 0.719. As all indicators are always larger than 0.50 , they all reach convergent validity.

Step 2: Internal consistency reliability

The measure of internal consistency reliability presents internal consistency based on the intercorrelations of the observed indicator variables (Sarstedt et al., 2021). Hair et al. (2009) gathered previous researches and identified the reliability for Cronbach's Alpha which is acceptable at 0.70. However, according to Peterson and Kim (2013), Cronbach's Alpha coefficient tends to evaluate reliability inaccurately; hence, the result from composite reliability (CR) can be considered to be closer to the value of reliability. The value of CR was between 0 and 1, which presents a higher reliability if closer to 1 . Sarstedt et al. (2021) claimed that a value of CR between 0.70 and 0.95 represents satisfactory-to-good reliability levels. The above conditions and Table 6 indicate that the Cronbach's Alpha values of the constructs were from 0.854 to 0.899 , while the CR values were between 0.901 and 0.922. Both Cronbach's Alpha and $\mathrm{CR}$ values were greater than 0.7 and less than 0.95 ; therefore, the internal consistency reliability of the indicators in the AG, FC, ITI, ODU, RI, and ED met the requirement of the scale.

Step 3: Discriminant validity

The discriminant validity assessment examines other constructs in the same model. Therefore, discriminant validity calculation shows that each construct is unique and points out the differences from other constructs in the model. The traditional approach to assess the accuracy in discrimination is the utilization of square root of AVE suggested by Fornell and Larcker (1981), while the modern approach is heterotrait - monotrait (HTMT) suggested by Henseler et al., (2015). When the HTMT value is higher than 0.90, that indicates that the constructs lack discriminant validity. In contrast, the constructs are considered distinct when the HTMT value is below or equal to 0.85 . Based on the above conditions and Table 4, the square root of AVE values were larger than the correlations between the latent variables (correlation coefficient is located below the first value of the column). In addition, Table 5 shows that the HTMT values were all less than 0.85 , so discriminant validity is guaranteed. 


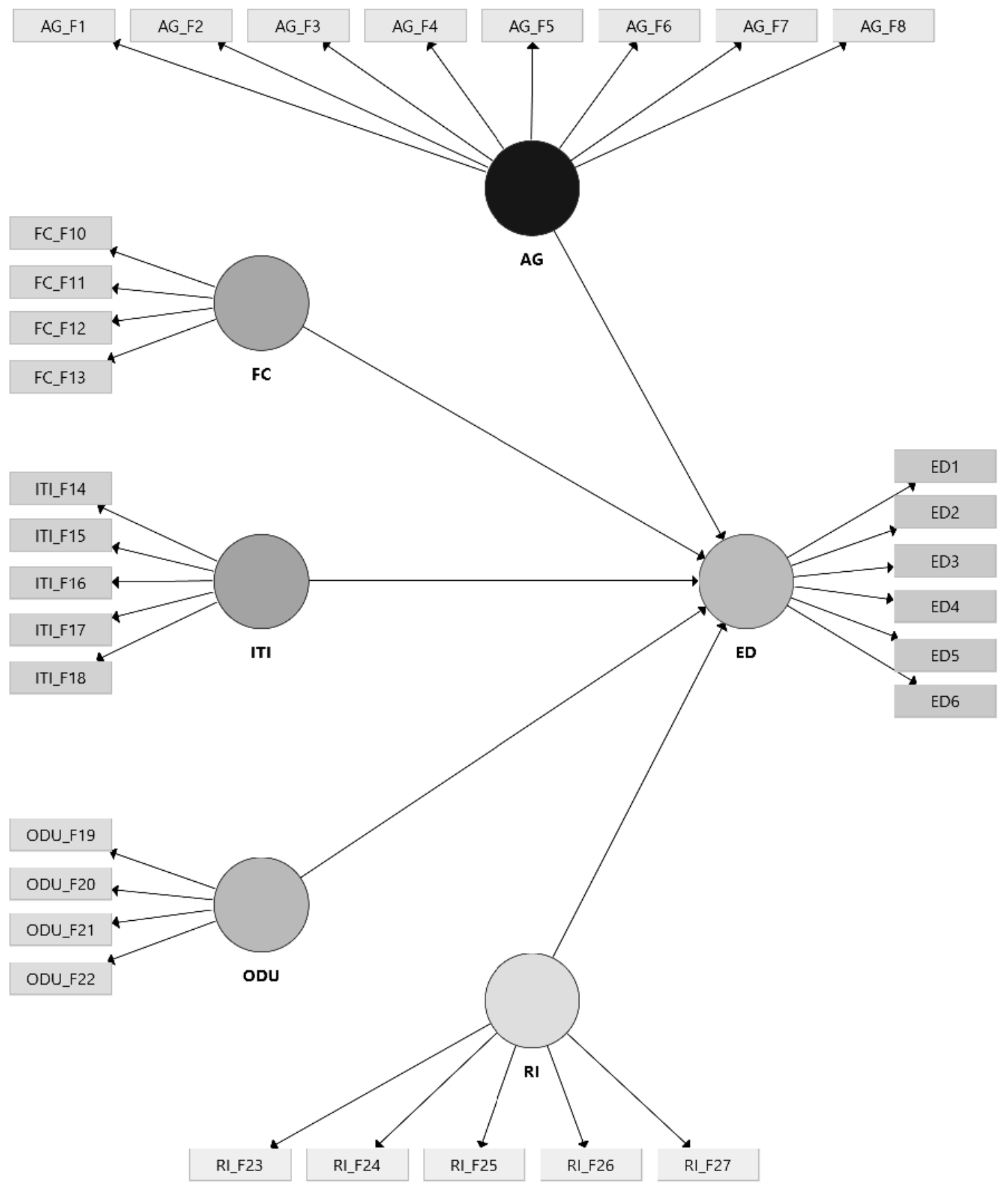

Figure 2. The PLS-SEM model

Based on the above conditions and Table 4, the square root of AVE values were larger than the correlations between the latent variables (correlation coefficient is located below the first value of the column). In addition, Table 5 shows that the HTMT values were all less than 0.85 , so discriminant validity is guaranteed. 
Table 4. Fornell-Larcker Criterion Analysis

\begin{tabular}{cllllll}
\hline Construct & AG & ED & FC & ITI & ODU & RI \\
\hline AG & $\mathbf{0 . 7 6 7}$ & & & & & \\
\hline ED & 0.568 & $\mathbf{0 . 7 8 2}$ & & & & \\
\hline FC & 0.311 & 0.646 & $\mathbf{0 . 8 4 8}$ & & & \\
\hline ITI & 0.284 & 0.617 & 0.447 & $\mathbf{0 . 8 1 6}$ & & \\
\hline ODU & 0.240 & 0.394 & 0.120 & 0.256 & $\mathbf{0 . 8 3 4}$ & \\
\hline RI & 0.247 & 0.310 & 0.077 & 0.075 & 0.311 & $\mathbf{0 . 8 3 8}$ \\
\hline \multicolumn{7}{l}{ Note: The value in bold is square root of AVE } \\
\hline
\end{tabular}

Note: The value in bold is square root of AVE

Table 5. The value of HTMT

\begin{tabular}{ccccccc}
\hline Construct & AG & ED & FC & ITI & ODU & RI \\
\hline AG & & & & & & \\
\hline ED & 0.631 & & & & \\
\hline FC & 0.345 & 0.734 & & & \\
\hline ITI & 0.318 & 0.695 & 0.511 & & \\
\hline ODU & 0.268 & 0.454 & 0.138 & 0.296 & \\
\hline RI & 0.271 & 0.342 & 0.088 & 0.106 & 0.356 \\
\hline
\end{tabular}

Table 6. Results summary for outer measurement model

\begin{tabular}{|c|c|c|c|c|c|c|c|}
\hline \multicolumn{2}{|c|}{ Latent Variable } & \multicolumn{3}{|c|}{ Convergent Validity } & \multicolumn{2}{|c|}{$\begin{array}{c}\text { Internal } \\
\text { Consistency } \\
\text { Reliability } \\
\end{array}$} & \multirow{2}{*}{$\begin{array}{c}\begin{array}{c}\text { Discriminant } \\
\text { Validity }\end{array} \\
\text { HTMT } \\
\text { confidence } \\
\text { interval does } \\
\text { not include } 1 \\
\end{array}$} \\
\hline Construct & $\begin{array}{c}\text { Indicator } \\
\mathrm{s}\end{array}$ & $\begin{array}{c}\text { Loading } \\
\mathrm{s}\end{array}$ & $\begin{array}{l}\text { Indicator } \\
\text { reliabilit } \\
y\end{array}$ & AVE & $\begin{array}{l}\text { Cronbach } \\
\text { 's alpha }\end{array}$ & CR & \\
\hline \multirow{8}{*}{ AG } & AG_F1 & 0.738 & 0.545 & \multirow{8}{*}{0.588} & \multirow{8}{*}{0.899} & \multirow{8}{*}{0.919} & \multirow{8}{*}{ Yes } \\
\hline & AG_F2 & 0.732 & 0.536 & & & & \\
\hline & AG_F3 & 0.751 & 0.564 & & & & \\
\hline & AG_F4 & 0.745 & 0.556 & & & & \\
\hline & AG_F5 & 0.783 & 0.614 & & & & \\
\hline & AG_F6 & 0.743 & 0.552 & & & & \\
\hline & AG_F7 & 0.869 & 0.754 & & & & \\
\hline & AG_F8 & 0.765 & 0.585 & & & & \\
\hline \multirow{4}{*}{ FC } & FC_F10 & 0.809 & 0.654 & \multirow{4}{*}{0.719} & \multirow{4}{*}{0.869} & \multirow{4}{*}{0.911} & \multirow{4}{*}{ Yes } \\
\hline & FC_F11 & 0.858 & 0.736 & & & & \\
\hline & FC_F12 & 0.872 & 0.760 & & & & \\
\hline & FC_F13 & 0.852 & 0.726 & & & & \\
\hline \multirow{5}{*}{ ITI } & ITI_F14 & 0.838 & 0.702 & \multirow{5}{*}{0.666} & \multirow{5}{*}{0.874} & \multirow{5}{*}{0.909} & \multirow{5}{*}{ Yes } \\
\hline & ITI_F15 & 0.751 & 0.564 & & & & \\
\hline & ITI_F16 & 0.861 & 0.741 & & & & \\
\hline & ITI_F17 & 0.838 & 0.702 & & & & \\
\hline & ITI_F18 & 0.789 & 0.623 & & & & \\
\hline \multirow{2}{*}{ ODU } & ODU_F19 & 0.596 & 0.596 & \multirow{2}{*}{0.696} & \multirow{2}{*}{0.854} & \multirow{2}{*}{0.901} & \multirow{2}{*}{ Yes } \\
\hline & ODU_F20 & 0.694 & 0.694 & & & & \\
\hline
\end{tabular}




\begin{tabular}{|c|c|c|c|c|c|c|c|}
\hline & ODU_F21 & 0.691 & 0.691 & & & & \\
\hline & ODU_F22 & 0.803 & 0.803 & & & & \\
\hline \multirow{5}{*}{ RI } & RI_F23 & 0.690 & 0.690 & \multirow{5}{*}{0.702} & \multirow{5}{*}{0.895} & \multirow{5}{*}{0.922} & \multirow{5}{*}{ Ye } \\
\hline & RI_F24 & 0.690 & 0.690 & & & & \\
\hline & RI_F25 & 0.730 & 0.730 & & & & \\
\hline & RI_F26 & 0.730 & 0.730 & & & & \\
\hline & RI_F27 & 0.680 & 0.680 & & & & \\
\hline \multirow{6}{*}{ ED } & ED1 & 0.815 & 0.664 & \multirow{6}{*}{0.612} & \multirow{6}{*}{0.873} & \multirow{6}{*}{0.904} & \multirow{6}{*}{ Yes } \\
\hline & ED2 & 0.798 & 0.636 & & & & \\
\hline & ED3 & 0.784 & 0.615 & & & & \\
\hline & ED4 & 0.801 & 0.641 & & & & \\
\hline & ED5 & 0.723 & 0.522 & & & & \\
\hline & ED6 & 0.772 & 0.595 & & & & \\
\hline
\end{tabular}

\subsection{Inner measurement model}

The process of assessment of inner measurement was conducted in five steps.

Step 1: Inner value of variance inflation factor (VIF) assessment

Multicollinearity happens when two or more formative constructs combine into one. J. J. F. Hair et al. (2017) suggested a multicollinearity threshold assessment depending on the VIF value. When the VIF value is higher than or equal to 5.0, it causes multicollinearity. When the VIF value is below 5.0 and above 3.3, it possibly causes multicollinearity. When the VIF value is lower than 3.3, it does not cause multicollinearity. Based on the above conditions and Table 7, the VIF values were all less than 3.3; therefore, multicollinearity does not appear in each component structure model.

Table 7. The value of inner VIF

\begin{tabular}{|c|c|c|c|c|c|}
\hline Construct & AG & ED & FC & ITI & OD \\
\hline AG & & 1.223 & & & \\
\hline ED & & & & & \\
\hline FC & & 1.312 & & & \\
\hline ITI & & 1.344 & & & \\
\hline ODU & & 1.196 & & & \\
\hline RI & & 1.150 & & & \\
\hline
\end{tabular}

Based on the above conditions and Table 7, the VIF values are all less than 3.3, therefore, multicollinearity does not appear in each component structure model.

Step 2: Statistical significance and relevance evaluation of structural model relationships

The structural model relationships consider whether exogenous latent variables have an impact on endogenous latent variables through direct and indirect effects (J. J. F. Hair et al., 2017). Depending on the bootstrapping method, the standardized beta coefficient $\left(\beta_{\mathrm{ij}}\right)$ is established. Statistical hypothesis is tested with hypothesis $H_{0}: \beta_{\mathrm{ij}}=0, H_{1}: \beta_{\mathrm{ij}} \neq 0$. The hypothesis gets rejected when $p<\alpha \quad\left(P_{\text {values }}<0.05\right)$ : beta coefficient is different from 0 ; accordingly, it indicates a significant relationship. 
Table 8. The value of path coefficient

\begin{tabular}{cccc}
\hline Hypothesis & Standardized beta & T Statistics & P Values \\
\hline AG -> ED & 0.287 & 6.273 & 0.000 \\
\hline FC -> ED & 0.388 & 7.866 & 0.000 \\
\hline ITI -> ED & 0.311 & 6.200 & 0.000 \\
\hline ODU -> ED & 0.156 & 2.981 & 0.003 \\
\hline RI -> ED & 0.137 & 2.642 & 0.008 \\
\hline
\end{tabular}

Based on the above conditions and Table 8 , statistics revealed that the beta coefficient is arranged in strong-to-weak effects (FC, AG, ITI, ODU, and RI). In addition, as $p$ values are all less than 0.05 , the effects are significant.

Step 3: Level of $R^{2}$ assessment

The aim of coefficient of determination $\left(R^{2}\right.$ value) assessment is to consider the in-sample explanatory power of both a substantial and weak analysis model in a cause-effect relationship (J. J. F. Hair et al., 2017; Rigdon, 2012). Its value is evaluated depending on $\mathrm{R}^{2}$, which is suggested by Henseler et al. (2009) as the $25 \%, 50 \%$, and $75 \%$ equivalent to weak, moderate, and substantial. However, according to the most current research of Sarstedt et al. (2021), based on the situation and concept, the researchers expected the value of $\mathrm{R}^{2}$ to be higher than $65 \%$. Based on the above conditions and Table 9, the exogenous latent variables explained $70 \%$ of the variation of the endogenous latent variable ED.

Table 9. The value of $R^{2}$ và $R^{2}$ adj

\begin{tabular}{rrr} 
& R Square & R Square Adjusted \\
\hline ED & 0.710 & 0.700
\end{tabular}

Step 4: The assessment of $\mathrm{f}^{2}$ impact

The aim of $\mathrm{f}^{2}$ assessment is to evaluate the importance of the exogenous construct in an explanation of endogeous contruct change in case the exogenous construct is omitted from the model (Chin, 1998). The formular of $\mathrm{f}^{2}$ :

$$
f_{i}^{2}=\frac{R_{\text {included }}^{2}-R_{\text {excluded }}^{2}}{1-R_{\text {included }}^{2}}
$$

where $R_{\text {included }}^{2}$ is equal to $\mathrm{R}^{2}$ of the model when the exogenous construct exists in the model, and $R_{\text {excluded }}^{2}$ is equal to $R^{2}$ of the model when the exogenous construct is omitted from the model.

This means that the exogenous construct omission from the model increased the in-sample nonexplanatory power of other exogenous constructs towards the change of endogenous contruct. As a guideline by Cohen (1988) in the assessment of exogenous construct importance, the value of $f^{2}$ was $0.02,0.15$, and 0.35 , equivalent to a small, medium, and large effect, respectively.

Based on the above conditions and Table 10, the variable with a strong influence ED variable was the FC variable, the variable with the a medium effect on the ED variable was the AG and ITI variable, and the variable with a small influence on the ED variable was the ODU and RI variable. 
Table 10. The value of $\mathrm{f}^{2}$

\begin{tabular}{cllllll}
\hline Construct & AG & ED & FC & ITI & ODU & RI \\
\hline AG & 0.233 & & & & \\
\hline ED & & & & & \\
\hline FC & 0.396 & & & \\
\hline ITI & 0.248 & & & \\
\hline ODU & 0.070 & & & \\
\hline RI & 0.056 & & & \\
\hline
\end{tabular}

Step 5: Predictive relevance $\mathrm{Q}^{2}$ assessment

A major misconception among analysts is using $\mathrm{R}^{2}$, which solely represents in-sample explanatory power as a representative for in-sample predictive power of the model (J. F. Hair, Risher, Sarstedt, \& Ringle, 2019). The $\mathrm{Q}^{2}$ value proposed by Geisser (1974); Stone (1974), and illustrated by Henseler, Ringle, and Sarstedt (2012); Tenenhaus, Vinzi, Chatelin, and Lauro (2005), is reflected in the following formula:

$$
Q^{2}=1-\frac{\sum_{D} S S E_{D}}{\sum_{D} S S E_{D}}
$$

where D is the specified omission distance of the endogenous variable, SSED is the sum of squared errors of prediction by omission distance, and SSOD is the sum of squares of observations by omission distance. The $\mathrm{Q}^{2}$ value is calculated by using blindfolding for a specified omission distance, depending on the "rule of thumb" of J. F. Hair et al. (2019). When the value is between 0 and 0.25 , from 0.25 to 0.50 , and higher than 0.50 , the predictive relevance is low, moderate, and high, respectively.

Table 11. The value of $\mathrm{Q}^{2}$

\begin{tabular}{cccc}
\hline & SSO & SSE & $\mathbf{Q}^{2}$ (=1-SSE/SSO) \\
\hline AG & 1200.000 & 1200.000 & \\
\hline ED & 900.000 & 525.456 & 0.416 \\
\hline FC & 600.000 & 600.000 & \\
\hline ITI & 750.000 & 750.000 & \\
\hline ODU & 600.000 & 600.000 & \\
\hline RI & 750.000 & 750.000 & \\
\hline
\end{tabular}

Based on the above conditions and Table 10 , as the $\mathrm{Q}^{2}$ value was greater than 0.2 and less than 0.5 , the predictive power of the model was of average accuracy.

\section{Discussion}

This study was conducted applying the PLS-SEM method to examine the influence of barriers on the effectiveness and development of ITS projects in Vietnam. By using this approach, the potential factors that have a direct impact on the effectiveness and development of an ITS project were clearly identified. Path model establishment for research is of the essence. By analyzing and evaluating all standardized beta coefficients in SEM, this study reveals that the potential barriers from FC are a primary cause for ITS project effectiveness and development. The structural modeling results show that approximately $70 \%$ of ITS effectiveness and development is affected by the lack of undivided attention from the government (AG), financial 
constraints for ITS (FC), inadequate attention or incomplete transport infrastructure (ITI), the over-development of urbanization (ODU). ), and the readiness and integration for ITS (RI), while $30 \%$ comes from other factors. It can be concluded that factors related to government, budget, outdated existing infrastructure, urbanization, and new system acceptance are the dominant factors that directly affect the sustainable development of new traffic facilities, and Table 6 proves the significant relationships of these factors with the effectiveness and development of an ITS project. Considering the importance of the five aforementioned barriers, the factor related to financial constraints (beta $=0.388$ ) has the largest influence on ITS projects.

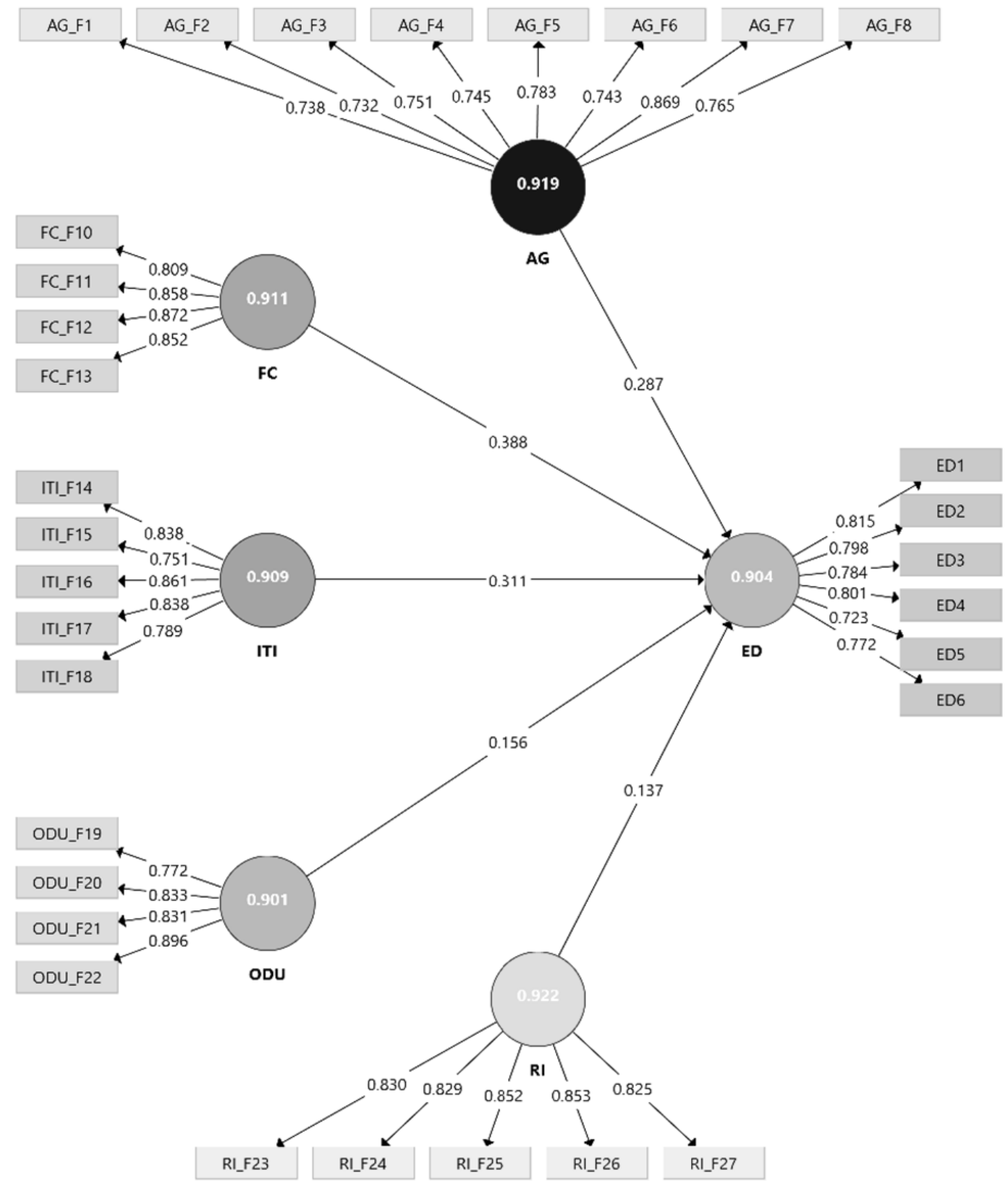

Figure 3. Estimation of PLS-SEM model

Factors related to financial constraints for ITS include four subfactors: the low level of limited demand for automation (factor loading $=0.809$ ), resources insufficiency for the 
maintenance and operation process (factor loading $=0.852$ ), enormous expenditures for ITS implementation/application (factor loading $=0.858$ ), and the high level of disruption during the implementation of an ITS project (factor loading $=0.872$ ). There still remains limitations in automation connection and communication between static components (such as roads and railways) and dynamic components (CCTV, traffic lights, and sensors on vehicles), which eventually results in hidden expenses in cities, and traffic congestion on roads and public transport systems caused by crowds of people living and working in close proximity (Booysen et al., 2013; Hsu et al., 2010). Moreover, water drainage systems can pose detrimental public health risks and floods due to the excessive number of activities in a specific place. The solution to these issues is comprehensive implementation, which is considered exorbitant because thorough land-use planning can contribute to the distribution of activities over multiple sites and determine the density that allows for a convergence effect (El.Husseiny et al., 2017; Mangiaracina et al., 2016). In addition, the following factors such as inadequate/incomplete transport infrastructure (beta $=0.311$ ), the lack of undivided attention from the government (beta $=0.287$ ), the over-development of urbanization (beta $=0.156$ ), and the readiness and integration for ITS (beta $=0.137$ ) are shown in Figure 3. In explanation of this model, the $\mathrm{R}^{2}$ value at $70 \%$ of the variance in effectiveness and development of ITS projects are explained by lack of government attention, budget constraints, the insufficiency of adequacy in transport infrastructure, policies to the over-development of urbanization, as well as readiness and integration for ITS. Among them, the financial limitation is directly related to the development of ITS at $\mathrm{T}=7.866$ and $\mathrm{P}=0.000$, showing that this is a significant predictor for ITS project effectiveness and development. The effect size of financial constraints was 0.396, showing that factors related to ITS greatly influence R2 for ITS project development. On the other hand, the reliability of the model is determined by the value of $\mathrm{Q}^{2}$ which was 0.416 , presenting the medium predictive power. In addition, it represents the predictive relevance model as $Q^{2}$ value is greater than 0 .

\section{Conclusion}

This research was conducted to collect the factors that potentially affect ITS. Thereby, they can be categorized into typical groups and discussed through the obtained results. It also provides some specific insights in terms of challenges, practices, and success factors that ITS brings to a smart city in particular and the country in general, and provides a general and comprehensive overview of the main issues of ITS faced by underdeveloped and developing countries. Explanation, provision of barriers, and preparation for ITS could describe the great potential that ITS creates for national socio-economic development. Accordingly, ITS needs to be researched in a more intensive and systematic way. Technological development has gradually changed governance and urban operation, as well as the creation of new job opportunities, a positive impact on the environment, and sustainable development for society. Limitations in our research are that it is not adequate for undeveloped countries and impractical for sea and air routes. The ranking of the factors of this study is mainly based on a small group of experts in Vietnam in order to arrange the factors, but it will be the basis for future survey data collection. Future research orientation will provide ITS criteria for specific types of transport and detailed guidelines for cooperation in ITS. We will conduct interviews with leading experts in Vietnam related to the field including Regional and Urban Planning, Transport Construction, and Architecture and Project Management, with the main purpose of developing a list of impacts on the effectiveness and development of an ITS project. 


\section{Acknowledgments}

We acknowledge the support of time and facilities from Ho Chi Minh City University of Technology (HCMUT), VNU-HCM for this study. The authors also would like to thank the Professional Knowledge \& Project Management Research Team (K2P), Ho Chi Minh City Open University, Vietnam for supporting this research.

\section{References}

Alam, M., Ferreira, J., \& Fonseca, J. (2016). Introduction to intelligent transportation systems. In Intelligent transportation systems (pp. 1-17). Springer, Cham. doi:https://doi.org/10.1007/978-3-319-28183-4_1.

Barclay, D., Thompson, R., \& Higgins, C. (1995). The Partial Least Squares Approach To Causal Modeling: Personal Computer Adoption And Use As Illustration. Technology Studies, 2, 285-309.

Booysen, M. J., Andersen, S. J., \& Zeeman, A. S. (2013, October). Informal public transport in Sub-Saharan Africa as a vessel for novel intelligent transport systems. In 16th International IEEE Conference on Intelligent Transportation Systems (ITSC 2013) (pp. 767-772). IEEE. doi:https://doi.org/10.1109/ITSC.2013.6728324.

Chin, W. W. (1998). The partial least squares approach to structural equation modeling. Modern methods for business research, 295(2), 295-336.

Cohen, J. (1988). Statistical Power Analysis for the Behavioral Sciences. Lawrence Erlbaum Associates.

Dapice, D., Gomez-Ibanez, J. A., \& Thanh, N. X. (2010). Ho Chi Minh City: Challenges for Growth. Retrieved from United Nations Development Programme: http://www.undp.org/content/dam/vietnam/docs/Publications/26503_HCM_Challenges _of_growth-VN.pdf (07.05.2021).

Dassani, N., Nirwan, D., \& Hariharan, G. (2015). Dubai - A New Paradigm For Smart Cities. Retrieved from KPMG: https://assets.kpmg/content/dam/kpmg/pdf/2016/04/Dubai-anew-paradigm-for-smart-cities-uae.pdf (12.09.021).

Dubow, J. (2014). Big Data And Urban Mobility. Retrieved from The World Bank: https:/www.worldbank.org/content/dam/Worldbank/Feature\%20Story/mena/Egypt/Eg ypt-Doc/Big-Data-and-Urban-Mobility-v2.pdf (12.05.2021).

El Husseiny, H. M., El Meligy, B., \& Hassan, M. (2017). The opportunities and challenges of applying intelligent transport systems (ITSS) on road transport in egypt: a case study on Cairo/Alexandria desert road. The Business \& Management Review, 8(5), 100-110.

Far, B., Chavoshy, A., rad, A. L., \& Mozaffari, G. (2013). Challenges Of Implementation Of Intelligent Transportation Systems In Developing Countries: Case Study - Tehran. WIT Press, 2(VIII), 977-987. doi:http://doi.org/10.2495/SC130832.

Finck, M., Lamping, M., Moscon, V., \& Richter, H. (2020). Smart Urban Mobility as a Regulatory Challenge. In Smart Urban Mobility (pp. 1-17). Springer, Berlin, Heidelberg. doi:https://doi.org/10.1007/978-3-662-61920-9_1.

Fornell, C., \& Larcker, D. F. (1981). Structural Equation Models with Unobservable Variables and Measurement Error: Algebra and Statistics. Journal of Marketing Research, 18(3), 382388. doi:10.1177/002224378101800313. 
Foster, J. (2021). ITS World Congress Preview. Retrieved from (10.11.2021).

Geisser, S. (1974). A Predictive Approach to the Random Effect Model. Biometrika, 61(1), 101-107. doi:10.2307/2334290.

Grant-Muller, S., \& Usher, M. (2014). Intelligent Transport Systems: The propensity for environmental and economic benefits. Technological Forecasting and Social Change, 82, 149-166. doi:10.1016/j.techfore.2013.06.010.

Hair, J. F., Risher, J. J., Sarstedt, M., \& Ringle, C. M. (2019). When to use and how to report the results of PLS-SEM. European Business Review, 31(1), 2-24. doi:10.1108/EBR-11-2018-0203.

Hair, J. J. F., Black, W. C., Babin, B. J., \& Anderson, R. E. (2009). Multivariate Data Analysis.

Hair, J. J. F., Hult, G. T. M., Ringle, C. M., \& Sarstedt, M. (2017). A Primer on Partial Least Squares Structural Equation Modeling (PLS-SEM): SAGE.

Henseler, J., Ringle, C. M., \& Sarstedt, M. (2012). Using partial least squares path modeling in advertising research: basic concepts and recent issues. In Handbook of research on international advertising: Edward Elgar Publishing.

Henseler, J., Ringle, C. M., \& Sarstedt, M. (2015). A new criterion for assessing discriminant validity in variance-based structural equation modeling. Journal of the Academy of Marketing Science, 43(1), 115-135. doi:10.1007/s11747-014-0403-8.

Henseler, J., Ringle, C. M., \& Sinkovics, R. R. (2009). The use of partial least squares path modeling in international marketing. In New challenges to international marketing. Emerald Group Publishing Limited, 20, 277-319. doi:https://doi.org/10.1108/S14747979(2009)0000020014.

Hidalgo, D., \& Huizenga, C. (2013). Implementation of sustainable urban transport in Latin America. Research in transportation economics, 40(1), 66-77. doi:https://doi.org/10.1016/j.retrec.2012.06.034.

Hsu, I. Y. Y., Wódczak, M., White, R. G., Zhang, T., \& Hsing, T. R. (2010). Challenges, approaches, and solutions in intelligent transportation systems. In 2010 second international conference on ubiquitous and future networks (ICUFN) (pp. 366-371). IEEE. doi:https://doi.org/10.1109/ICUFN.2010.5547180.

ISO. (2019). ISO 37122:2019 Sustainable cities and communities - Indicators for smart cities. In. International Organization for Standardization.

ISO. (2020). ISO/TC 204 Intelligent Transport Systems. In: International Organization for Standardization.

John, S. K., Sivaraj, D., \& Mugelan, R. K. (2019). Implementation Challenges and Opportunities of Smart City and Intelligent Transport Systems in India. In Internet of Things and Big Data Analytics for Smart Generation (pp. 213-235). Springer, Cham. doi:https://doi.org/10.1007/978-3-030-04203-5_10.

Karim, Z., \& Fouad, J. (2018a). An analysis of public bus transport performance and its determinants factors: The case of major Morocco's cities. In 2018 International Colloquium on Logistics and Supply Chain Management (LOGISTIQUA) (pp. 44-50). IEEE.

Karim, Z., \& Fouad, J. (2018b). Measuring urban public transport performance on route level: A literature review. In MATEC Web of Conferences (Vol. 200, p. 00021). EDP Sciences. 
Khekare, G. S., \& Sakhare, A. V. (2013). A smart city framework for intelligent traffic system using VANET. In 2013 International Mutli-Conference on Automation, Computing, Communication, Control and Compressed Sensing (iMac4s) (pp. 302-305). IEEE. doi:https://doi.org/10.1109/iMac4s.2013.6526427.

Khorasani, G., Tatari, A., Yadollahi, A., \& Rahimi, M. (2013). Evaluation of Intelligent Transport System in Road Safety. IJCEBS, 1(1), 110-118. doi:http://doi.org/10.12691/jfe-4-5-1.

Kitchenham, B. (2004). Procedures for performing systematic reviews. Keele, UK, Keele University, 33(2004), 1-26.

Komninos, N. (2006). The architecture of intelligent clities: Integrating human, collective and artificial intelligence to enhance knowledge and innovation. In 2006 2nd IET International Conference on Intelligent Environments-IE 06 (Vol. 1, pp. 13-20). IET.

Latan, H., \& Noonan, R. (2017). Partial Least Squares Path Modeling: Basic Concepts, Methodological Issues and Applications. Springer.

Lazaroiu, G. C., \& Roscia, M. (2012). Definition Methodology For The Smart Cities Model. Energy, 47(1), 326-332. doi:http://doi.org/10.1016/j.energy.2012.09.028.

L Lin, Y., Wang, P., \& Ma, M. (2017). Intelligent transportation system (ITS): Concept, challenge and opportunity. In 2017 ieee 3rd international conference on big data security on cloud (bigdatasecurity), ieee international conference on high performance and smart computing (hpsc), and ieee international conference on intelligent data and security (ids) (pp. 167-172). IEEE.

Mangiaracina, R., Perego, A., Salvadori, G., \& Tumino, A. (2016). A Comprehensive View Of Intelligent Transport Systems For Urban Smart Mobility. International Journal of Logistics Research and Applications, 20(1), 39-52. doi:https://doi.org/10.1080/13675567.2016.1241220.

Mathew, E. (2019, October). Intelligent Transport Systems and Its Challenges. In International Conference on Advanced Intelligent Systems and Informatics (pp. 663-672). Springer, Cham. doi:https://doi.org/10.1007/978-3-030-31129-2_61.

Metz, B., Davidson, O., Bosch, P., Dave, R., \& Meyer, L. (2007). Climate Change 2007: Mitigation of Climate Change.

Peterson, R. A., \& Kim, Y. (2013). On the Relationship Between Coefficient Alpha and Composite Reliability. Journal of Applied Psychology, 98(1), 194-198. doi:http://www.doi.org/10.1037/a0030767.

Prabhu, S. B., Balakumar, N., \& Antony, A. J. (2017). A research on smart transportation using sensors and embedded systems. International Journal of Innovative Research in Computer Science \& Technology (IJIRCST). doi:https://doi.org/10.21276/ijircst.2017.5.1.5.

Qin, H., \& Zhang, W. (2011). Charging scheduling with minimal waiting in a network of electric vehicles and charging stations. In Proceedings of the Eighth ACM international workshop on Vehicular inter-networking (pp. 51-60).

Rigdon, E. E. (2012). Rethinking partial least squares path modeling: In praise of simple methods. Long range planning, 45(5-6), 341-358. doi:https://doi.org/10.1016/j.1rp.2012.09.010.

Ringle, C. M., Wende, S., \& Becker, J.-M. (2015). SmartPLS 3 (Version 3.3.3): Bönningstedt: SmartPLS. Retrieved from https://www.smartpls.com/ (05.05.2021). 
Roselló, X., Langeland, A., \& Viti, F. (2016). Public Transport in the Era of ITS: The Role of Public Transport in Sustainable Cities and Regions. In G. Gentile \& K. Noekel (Eds.), Modelling Public Transport Passenger Flows in the Era of Intelligent Transport Systems: COST Action TU1004 (TransITS) (pp. 3-27). Cham: Springer International Publishing.

Russo, F., Rindone, C., \& Panuccio, P. (2014). The Process Of Smart City Definition At An EU Level. WIT Press, 2. doi:http://doi.org/10.2495/SC140832.

Sampson, E. (2019). Smart Mobility, Empowering Cities. Retrieved from ITS World Congress Singapore: https://erticonetwork.com/wp-content/uploads/2020/03/ITSWC-2019-PostEvent-Report-v4-final.pdf (16.05.2021).

Sarstedt M., Ringle C.M., Hair J.F. (2021) Partial Least Squares Structural Equation Modeling. In: Homburg C., Klarmann M., Vomberg A.E. (eds) Handbook of Market Research. Springer, Cham. https://doi.org/10.1007/978-3-319-05542-8_15-2.

Schlingensiepen, J., Nemtanu, F., Mehmood, R., \& McCluskey, L. (2016). Autonomic transport management systems-enabler for smart cities, personalized medicine, participation and industry grid/industry 4.0. In Intelligent transportation systems-problems and perspectives (pp. 3-35). Springer, Cham. doi:https://doi.org/10.1007/978-3-319-19150-8_1.

Sen, R., \& Raman, B. (2012). Intelligent transport systems for Indian cities. In 6th USENIX/ACM Workshop on Networked Systems for Developing Regions (\{NSDR\} 12).

Stone, M. (1974). Cross-Validatory Choice and Assessment of Statistical Predictions. Journal of the Royal Statistical Society. Series B (Methodological), 36(2), 111-147.

Sun, J. (2011). Development and Strategies for the Intelligent Transport System in China. In ICTIS 2011: Multimodal Approach to Sustained Transportation System Development: Information, Technology, Implementation (pp. 1263-1267). doi:https://doi.org/10.1061/41177(415)161.

Tenenhaus, M., Vinzi, V. E., Chatelin, Y.-M., \& Lauro, C. (2005). PLS path modeling. Computational Statistics \& Data Analysis, 48(1), 159-205. doi:https://doi.org/10.1016/j.csda.2004.03.005.

Tuominen, A., \& Ahlqvist, T. (2010). Is the transport system becoming ubiquitous? Sociotechnical roadmapping as a tool for integrating the development of transport policies and intelligent transport systems and services in Finland. Technological forecasting and social change, 77(1), 120-134. doi:https://doi.org/10.1016/j.techfore.2009.06.001.

Tyrinopoulos, Y., \& Antoniou, C. (2013). Factors affecting modal choice in urban mobility. European Transport Research Review, 5(1), 27-39. doi:https://doi.org/10.1007/s12544-0120088-3.

United-Nations. (2018). World Urbanization Prospects The 2018 Revision Retrieved from New York: $\quad$ https://population.un.org/wup/Publications/Files/WUP2018-Report.pdf (21.04.2021).

Zeng, N., Yan Liu, P. G., Hertogh, M., \& König, M. (2021). Do Right PLS And Do PLS Right: A Critical Review Of The Application Of PLS-SEM In Construction Management Research. Frontiers of Engineering Management, 356-369. doi:https://doi.org/10.1007/s42524-021-0153-5. 